\title{
RETRANSLATING JOYCE'S ULYSSES INTO SPANISH: AN INTERVIEW WITH FRANCISCO GARCÍA TORTOSA AND MARÍA LUISA VENEGAS LAGÜÉNS
}

Guillermo Sanz Gallego 1 ${ }^{1}$ Ghent University, Ghent/Vrije Universiteit, Brussel, Bélgica

\section{Introduction}

James Joyce's Ulysses has broadly been considered as the most influential work of literature of the $20^{\text {th }}$ century. It is also one of the most challenging works for a literary translator. The work has been translated and retranslated to a significant number of languages. International conferences on Joyce's work are held every year, and translation is one of the recurring topics of panels and papers. In fact, one can frequently find panels and papers on Joyce's work in translation conferences as well.

During the $26^{\text {th }}$ International James Joyce Symposium (University of Antwerp, 2018) two panels on translation were held, a circumstance that shows the relentless interest of translation within Joyce studies. There were papers on translations into Dutch, French, Hungarian, Italian, Macedonian, and Spanish. One of the main points of interest was the study of retranslations. Some of the main research questions on this topic deal with the ageing process of translations as a reason for retranslations. Other contributions intend to reveal the added value of retranslations, which is indeed a challenging enterprise that can only be fulfilled by means of a thorough and meticulous comparative analysis of source text, translation, and retranslations. By interviewing the two translators 
of the third Spanish translation of Ulysses, the present contribution aims at both shedding light on the translation process of this work, and at highlighting the importance of retranslations within cultural and literary transfer.

\section{The third Spanish translation by Tortosa and Venegas: Why we should read retranslations}

Francisco García Tortosa and María Luisa Venegas Lagüéns published the third Spanish translation of Ulysses in 1999. Apart from translating Ulysses into Spanish, Tortosa and Venegas have lectured a significant number of courses within the Department of English and North-American Literature at the University of Seville, Spain. I had the privilege and honour of attending their lectures at undergraduate and postgraduate level on, among other topics, English literature, textual analysis, criticism, cultural studies, film studies, translation, and Joyce's work. My fellow students and I highly appreciated their teaching methods, and their constructive feedback regarding our assignments and essays.

Unlike their predecessors, both Tortosa and Venegas have an academic background and profile related to literature, translation, and linguistics. Salas Subirat, the author of the first translation published in Buenos Aires in 1945, was an employee in an insurance agency. José María Valverde, who published the second translation in Barcelona in 1976, was a Spanish professor whose main field of expertise was philosophy. Accordingly, one can expect a priori a higher level of quality in the translation signed by Tortosa and Venegas. Yet, one must also give credit to the translations by Salas Subirat and Valverde, because translating Ulysses implies an extremely challenging endeavour. Given that the three translations have managed to stand the test of time, it is also legitimate to compare them within the framework of a crossed methodology on retranslation. 
My colleague Kris Peeters from the University of Antwerp and myself delivered a joint paper at the last Joyce international conference in Antwerp in June 2018 in which we discussed the Dutch and Spanish translations and retranslations of Ulysses. After carrying out a comparative analysis of 'Oxen of the Sun', one of the most challenging episodes for translators, we managed to confirm that two retranslations, namely the third Dutch translation by Bindervoet and Henkes, and the third Spanish translation by Tortosa and Venegas, are both more source oriented and more target oriented.

Unlike first translations, retranslations tend to avoid explicitation, a translation strategy that points toward one specific interpretation of the text. Instead, retranslations are more source oriented in the sense that they provide a wider spectrum of interpretations, comparable to the source text. Simultaneously, they are also more target oriented in the sense that, unlike former translations, they pay more attention to style in the form of prosodic elements, heterology and heteroglossia, as well as to the reproduction of the narrator's dialogical voice in the case of Joyce's work. In our study we selected a series of passages from the 'Oxen of the Sun' chapter and carried out a test in which we focused on all these elements. The results proved that both the Dutch retranslation by Bindervoet and Henkes and the Spanish retranslation by Tortosa and Venegas manage to reproduce Joyce's work with more attention and accuracy, whereas some of the former translations seem to have ignored some of these elements. The whole analysis in the form of a scholarly piece is at the time of publication of this article under peer review for publication. 


\section{INTERVIEW WITH FRANCISCO GARCÍA TORTOSA AND MARÍA LUISA VENEGAS LAGÜÉNS}

Cadernos de Tradução (CT): According to Maarten Steenmeijer, a translation is aged after 30 years. Was age the main reason for this retranslation? Were the two other translations aged or do you believe that other aspects played an important role as well? To what extent can a retranslation be understood as a claim that the former translations could be improved?

Luisa Venegas Lagüéns (LVL): Age did not play such an important role. Salas Subirat's translation was incomplete. I did not consult Valverde's translation, since I found a lack of coherence and errors of interpretation when I looked up a couple of passages, so I did not read any further. It was a matter of a higher level of knowledge of languages. Twenty-five years ago English was less well known by Spaniards than today. Therefore, it is not surprising that the two former translations contained mistakes.

Francisco García Tortosa (FGT): I do not agree with Steenmeijer. A period of 30 years is too short for a translation. We did not translate Ulysses because the other two translations were aged, or because of the use of language. Valverde's translation contained many basic mistakes and misreadings. I believed a new translation was needed in order to correct Valverde's mistakes. A new translation had to reproduce the style of the source text in a more accurate way. Neither Salas Subirat nor Valverde paid any attention to the evolution of language in their translations of 'Oxen of the Sun'. In our translation we started with Alfonso X's style, then with don Juan Manuel, Cervantes, etc. Valverde made up a new language, a sort of new alternative Spanish, awkward for the Spanish reader. Adapting the language in Ulysses to the 
Spanish text was definitely one of the most challenging aspects we had to deal with. Salas Subirat and Valverde did not manage to reproduce sexual references in their translations, whereas our translation published by Cátedra did not change the register in those passages. I only checked the two former translations at very specific moments during the translation process. I checked Salas Subirat's translation less than Valverde's. As regards source texts, we used different editions for our translation. The main source text was the Gabler edition, but we also used the Penguin edition, and the 1934 reedition.

(CT): What were the main challenges of the translation process of such a work of literature?

(LVL): My colleague Francisco Tortosa had proposed a translation with eight other colleagues, with him in charge as a moderator. After a few months, people started dropping the project, because they believed it wasn't viable. We started translating Ulysses, and once a week we met to discuss a few lines or a paragraph. Therefore the rhythm was extremely slow. Some colleagues stopped altogether, so the process had to be redefined, and we began discussing larger passages. Soon it was Tortosa and I that went on with the plan. We met once in a while to deliberate on the translation of longer passages. There was not much time for meetings.

(CT): What are the main features of each translation?

( $L V L)$ : It is difficult to say. Valverde's translation seems to have been the product of a group of associates because there was little cohesion from one chapter to another.

$(F G T)$ : There were significant differences. My colleague María Luisa Venegas and I are specialists within language and literature, 
we have been professors within these fields of study. One needs to be aware of the evolution of the English language. Then suitable equivalent solutions must be found for the target language by means of an imitation of the style of Spanish literature throughout different historic periods. I have taught a number of courses on the evolution of languages. Valverde used to say he used the French and the German editions of Ulysses for his translation, whereas we only used the English text. Valverde translated Ulysses in one year, whereas we needed seven years. The Cátedra edition was carried out very slowly, there was no rush, every little detail was discussed for our translation.

(CT): Throughout Ulysses, Joyce portrays some characters by means of their use of language. For instance, Molly's limited cultural background is expressed by means of her incorrect grammar. What approach did you apply when you had to deal with such instances? Were you afraid of being corrected by your editors or by reviews in literary journals? How did you perceive the main characters of Ulysses - Stephen, Bloom, and Molly - in the former translations and how did you want to portray them in your translation?

( $L V L)$ : Since I did not use the two former translations, I do not know the focus they were given in these. I tried to define them as I thought Joyce had characterized them. I tried to grasp that and then I portrayed them by means of their language, of their distinctive way of speaking. For instance, I tried to imitate the substandard English Molly uses. As to sources, I did not consult many, but Gifford was a main reference to check allusions and, of course, I relied on my own reading of English-speaking writers.

(FGT): Unlike the two former translations, characters have their own voice in this edition. In our translation the reader will observe differences depending on the character's voice; for instance, 'Eumaeus' is narrated with Bloom's voice, and that is why it is such 
a confusing chapter for the reader, whereas 'Penelope' displays Molly's voice, full of vulgar language.

(CT): Were you tempted to make use of footnotes?

$(L V L)$ : Footnotes were not allowed by Cátedra, so it had to be made obvious in the text. It was not difficult for me to render Molly's incorrect use of the English language into incorrect Spanish, since I am familiar with substandard registers of both languages. Our target reader would realize that Molly's utterances were not mistakes made by the translators, since the consistent use of substandard language would make it evident. We took substandard Spanish to portray Molly, but we tried to avoid stereotypes from different regions.

(FGT): I decided to replace footnotes by an extended 200-page introduction. My colleague María Luisa Venegas is bilingual, so I have to give her all the credit for tracing and reproducing slang. That is one of the reasons I wanted her to translate Ulysses with me. She was very meticulous in her translations.

(CT): Unlike English, Spanish is a language in which second person can be polite ('usted') or more familiar ('tu'). Are there differences in the relationships between characters depending on the translation?

(FGT): Our translation had to make sense. Our Ulysses, the one we had in mind, was our stylesheet in order to establish relationships between characters. I wanted to deviate from Valverde's translation, but I don't know whether we managed to achieve it. We should ask María Luisa Venegas.

(LVL): Yes. We argued about this issue quite often. I always thought that since Ulysses was written at the beginning of the $20^{\text {th }}$ 
century, we had to go back to that epoch, to how our parents used to speak to each other, for instance. Right now we tend to use the 'tú' form too often in Spanish, whereas in the past they tended to use the 'usted' form.

(CT): Joyce develops his own language throughout Ulysses. Did you find many instances of what Newmark calls 'unfindable words' or untranslatable words? Or did you prefer to focus on sentence units? Also, to what extent were the two former translations reliable sources to solve these problems?

( $L V L)$ : As I have said above, I avoided the other translations completely. For compound words, I tried to think like Joyce. I retranslated the work many times. I translated a first time to grasp the meaning in English, then a second time in order to make it more prosodic, musical, rhythmical... Sometimes I left a word in English in capital letters so as not to break the rhythm and structure of the sentence; then I looked it up later and tried to fit it in the sentence. I wanted to work in sentence units and I tried to translate a page a day. To encourage myself, I would write the date on top of the page. Then, when I was revising a second or third time, sometimes I found myself converging on the same date, but a year or two later, on the same page.

$(F G T)$ : Sometimes we checked something in the former translations, but we tried to avoid those solutions for our translation. Our translation unit was the sentence, although 'Penelope' contains only eight sentences. In Joyce's work it is extremely difficult to make a difference between a sentence and a paragraph.

(CT): Did you agree beforehand on the kind of approach and translation you intended to produce? Did you aim at a higher level of domestication, or foreignization? 
$(L V L)$ : No, we never discussed that. I wanted to domesticate the translation from the beginning. I wanted to go back to the Spanish of the beginning of the $20^{\text {th }}$ century. Yet, sometimes we wanted to provide a foreign flavor.

(FGT): None of us wanted to help the reader. If the English text was ambiguous, the Spanish text had to be ambiguous too. If the use of a specific word class could imply a specific interpretation of the text, then we tried to look for an alternative option. Our translation domesticates more than any other in 'Oxen of the Sun'.

(CT): What kind of reader were you translating for? Did you have a specific profile in mind, such a Joycean? How could you depict your reader?

(FGT): I wanted to address a reader with an average cultural background, not only scholars.

$(L V L)$ : My target reader was an average reader with a certain cultural background, like my students, not necessarily an academic. During the presentation of the translation I remember Alfonso Guerra said that if the reader read the Introduction, he would understand the work, but I corrected him and said that the reader needed to read the work first if he wanted to understand it. With respect to the potential reader of Ulysses, my view is that he or she would be aware of English literature and culture, and I believe the average Spaniard would be up to it. If a reader cannot grasp irony, he would be lost reading Ulysses. Our target was the average, cultivated and aware Spanish reader.

(CT): Were you tempted to add any information in order to make the work accessible for a Spanish reader? Were you tempted to omit 
any information that could be considered somehow unnecessary for the Spanish reader?

$(F G T)$ : We never omitted or added anything. Additional information and explanations of the text can be found in the introduction, that is the purpose of that section.

$(L V L)$ : Never. I followed the source text word by word, Gabler's edition. Yet, I had to be inventive sometimes, because I had to make a pun or joke that could be recognizable by the Spanish reader. One example can be found in the peer pun in 'Nestor', when Stephen is at school. Also, in episode 8, Bloom is having lunch and talking about the provisions at the bar; he was referring to the mustard can, and we translated it as 'Cam-arón y sus descendientes se amostazaron y empanaron allí' (195).

(CT): What level of responsibility do translators have in the reception of a work of literature? Do Spaniards read Joyce more now than in the '80s or in the '90s?

$(F G T)$ : I think translators are indeed responsible for the reception of the work. Also, conferences on Joyce have an influence on the sales of our translation. Our translation was sold out yesterday [29 September 2017] at one of the most important book stores in Seville.

$(L V L)$ : I don't think Spaniards are reading Joyce that much right now, but 10 years ago they were definitely reading more Joyce than ever.

(CT): Let's go back to Steenmeijer's quote. Your translation is already 18 years old. Does it age well? 
$(L V L)$ : It really does. In fact, it is like good wine. We don't want a translation of Ulysses in colloquial Spanish, we want it like Joyce wrote it.

(FGT): In terms of sales, one must admit that the first years were better. The first edition was published in 1999, the second edition was being sold just after one year and a half, in 2001, the third one in 2004 ... It was impressive.

(CT): You translated Ulysses together. The last Dutch Ulysses was also translated by two translators? Is this a trend? Is this the most appropriate way?

(FGT): I think this is the best way to translate this work, because each translator discusses his colleague's work. Both translators are involved in the project. A proofreader would not have been that involved.

$(L V L)$ : I don't think it is a good idea. I would rather prefer one translator and then one proofreader. It is essential to have an external reader who does not call himself a translator.

(CT): What are the most useful pieces of advice you could give to those who intend to translate a work of literature?

(FGT): Do not translate with a deadline.

( $L V L)$ : Apart from the knowledge of the two languages, I would recommend reading a series of works written at that same period in the target language to get familiar with that style and language. That is extremely helpful. 
(CT): How was the contact with Cátedra, the publishing house of your translation?

(FGT): Cátedra gave us carte blanche in our translation. In the beginning they were in a hurry, they wanted to publish the translation as soon as possible. There were no problems with the submission dates of the manuscript. Yet, we had to face an embargo. Cátedra did not bear in mind the copyright of the original work. They mistakenly believed the copyright expired after twenty years. Yet, it expired after ninety years. Cátedra published the translation, and Joyce's grandson threatened the publishing house with legal action. The translation was embargoed two months after the publication. It was extremely sad, seven years of work thrown away. However, Cátedra managed to solve the problem in less than a year... a compensation was paid to Joyce's grandson, of course.

Recebido em: 12/09/2018 Aceito em: 01/11/2018 Publicado em janeiro de 2019

Guillermo Sanz Gallego. E-mail: Guillermo.SanzGallego@UGent.be ORCID: https://orcid.org/0000-0003-2945-4615 